\title{
Inherited thrombophilia and recurrent pregnancy loss: a single-center case-control study in North-Western Algeria
}

\author{
Ilhem Nassour-Mokhtari ${ }^{1}$, Bouchra Loukidi ${ }^{1}$, Abdellatif Moussouni ${ }^{2,3^{*}}$ (D) Reda Bettioui ${ }^{3}$, Riad Benhabib ${ }^{4}$,
} Hafida Merzouk', Amaria Aouar ${ }^{3}$ and Katia Allal-Taouli ${ }^{1,5}$

\begin{abstract}
Background: Recurrent pregnancy loss (RPL) is a common disorder that affects around 3 to $5 \%$ of pregnant women. It has different causes, and in about 50\%, it is of unknown etiology. Thrombophilia might increase the risk of RPL by adversely affecting the normal placental vascular function. Our study aimed to determine the frequency of factor V Leiden (FVL) and prothrombin G20210A gene mutations in Algerian women with RPL and to correlate their presence with the occurrence of such health's problem. A total of 80 women with previous fetal losses and 100 age-matched women with no history of fetal loss were recorded. Participants were tested for activated protein $C$ resistance (APCR), protein $C(P C)$, protein $S(P S)$, and antithrombin (AT) deficiencies. The screening of FVL and prothrombin G20210A mutations was also done using a duplex polymerase chain reaction.
\end{abstract}

Results: APCR was detected in $6.25 \%$ of cases and was absent in controls $(p=0.011)$. PC and PS deficiencies were documented in $7.5 \%$ of patients. FVL was detected in $8.33 \%$ of patients and was absent in controls $(p=0.047)$. Prothrombin G20210A mutation was found in $8.33 \%$ of patients compared to $11.11 \%$ of controls $(p=0.631)$. A significant association of FVL mutation with the abortion which occurred in the second trimester was found $(p=$ 0.001).

Conclusion: There is a significant association between FVL mutation and RPL especially the loss occurring during the second trimester. No correlation was found regarding prothrombin G20210A mutation.

Keywords: Recurrent pregnancy loss, Thrombophilia, FVL, APCR

\section{Background}

Recurrent pregnancy loss (RPL) represents a significant health problem with a rate of $5 \%$ among women in the reproductive age [1]. RPL or miscarriage can be defined as the loss of three or more successive pregnancies before viability and includes all pregnancy losses from the time of conception until 24 weeks of gestation [2]. Miscarriages can be subdivided into early pregnancy losses

\footnotetext{
* Correspondence: abdellatif.moussouni@gmail.com

${ }^{2}$ National Center for Prehistoric, Anthropological and Historical Research (CNRPAH, Tlemcen's station), 03, Rue Franklin Roosevelt, 16500 Alger, Algeria 'Laboratory of Human Actions' Valorisation for Protection of Environment and Application in Public Health, University of Tlemcen, 22, Rue Abi Ayed Abdelkrim Fg Pasteur B.P 119, 13000 Tlemcen, Algeria

Full list of author information is available at the end of the article
}

(which are most common) that occur before the 12th week of gestation and late pregnancy losses that occur in the 12th week to 21 st week of gestation [3, 4]. The cause of recurrent miscarriage remains unknown (idiopathic) in more than $50 \%$ of cases [5]; however, various genetic, anatomical, endocrine, and infective factors as well as thrombophilic states have been implicated [6].

Thrombophilia is defined as a predisposition to arterial or venous thrombotic complications as a result of hemostatic system defects [7]. It may be acquired, like the antiphospholipid syndrome, or inherited [8]. Thrombotic disorders are common cause of RPL and may be seen in $40-50 \%$ of cases [9]. In fact, pregnancy is a hypercoagulable state, and if the pregnancy is affected by 
thrombophilia, the hypercoagulable state becomes worse and may impair blood flow through the maternal veins, leading to deep vein thrombosis, and clots in the placental blood vessels, leading to fetal growth restriction and/ or fetal demise [10]. Factors associated with thrombophilia include factor $\mathrm{V}$ Leiden $(F V L)$ mutation, activated protein C resistance (APCR), prothrombin G20210A gene mutation, protein $\mathrm{C}$ (PC) deficiency, protein $\mathrm{S}$ (PS) deficiency, antithrombin III (AT III) deficiency, and endothelial cell dysfunction [11].

The polymorphisms G20210A of prothrombin gene and G1691A of factor V gene are the most extensively studied thrombophilic mutations in association to recurrent miscarriage [12]. Previous studies have reported prevalence of FVL mutation among women with recurrent miscarriage ranging from 3 to $42 \%$ [13], while its prevalence in Caucasian population is 4 to $7 \%$ [14]. FVL mutation is autosomal dominant disorder in which the glutamine to arginine missense mutation occurs at nucleotide 1691 of the factor $\mathrm{V}$ gene [15]. The resulting arginine (Arg) at amino acid 506 is substituted with glutamine (Gln), and this factor V mutation induces the APCR and contributes to increased risk of thrombosis [15].

The prothrombin G20210A mutation results from $\mathrm{G}$ to A substitution at position 20,210 in the $3^{\prime}$-untranslated region of the prothrombin gene; it induces high plasma levels of thrombin [16] and facilitates clot formation in heterozygous individuals, who have a twofold higher risk of clotting in comparison to non-carriers $[17,18]$.

Many studies done worldwide have shown a significant correlation between FVL and RPL [19]. This approach may be helpful to solve this major health problem by an appropriate antithrombotic treatment [20]. In Algeria, there is a lack of data regarding $F V L$ and thrombophilia implication in general in recurrent abortions. For this reason, a case-control study was planned.

The main goal of this study was to determine the frequency of prothrombin G20210A and FVL polymorphisms and to correlate their presence with RPL occurring in local population. The frequencies of APCR, PC, and PS deficiencies were also determined.

\section{Methods}

\section{Patients and controls}

The case-control study was conducted at the laboratory of Hematology, Hospital of Tlemcen, Algeria, from January 2016 to July 2017, after getting approval from the institutional ethics committee. Informed consent was obtained from all the cases and the controls.

Eighty women of reproductive age (19-45 years) with history of at least 3 unexplained miscarriages before 10 weeks of amenorrhea (WA) or at least 2 late miscarriages between 10 and $16 \mathrm{WA}$ or at least one intrauterine fetal demise (IUFD) beyond 16 weeks were included as cases, while 100 age-matched females with at least one live-born children and no personal history of pregnancy loss were taken as controls. The definition of IUFD in terms of gestational age varies across geographical settings [21]. In our study, we defined it as the death of an unborn baby at 16 weeks' gestation or more.

Those excluded from among the cases were patients with chronic pathologies (arterial hypertension, diabetes), pregnant ones, and women taking anticoagulant medications.

A uniform questionnaire was used to collect information about age, residency, parity, medical and obstetric history, consanguineous marriage, and familial history of miscarriage. Data were collected by direct interview between the researcher and each participant.

\section{Laboratory evaluation}

Venous blood was collected on $0.109 \mathrm{M}$ tri-sodium citrate and was centrifuged twice at $2500 \mathrm{~g}$ for $15 \mathrm{~min}$ at room temperature in order to obtain plasma with relatively few remaining platelets. Plasma was then frozen and stored in small aliquots at $-20^{\circ} \mathrm{C}$ until tested. Ethylene diamine tetraacetic acid (EDTA) anticoagulant samples were used for deoxyribonucleic acid (DNA) analysis. EDTA blood was immediately stored at $-40{ }^{\circ} \mathrm{C}$.

Women in both the control and study groups underwent the below-mentioned tests: prothrombin time (PT), activated partial thromboplastin time (APTT), fibrinogen, APCR, and prothrombin. Women in the study group additionally underwent the following tests: PC, PS, and AT.

\section{Phenotypic tests}

The analysis was carried out at the Thrombosis Unit. Before examining the blood sample, the plasma was thawed in a water bath for $15 \mathrm{~min}$ at a temperature of $37^{\circ} \mathrm{C}$. All tests were performed by the fully automatic clinical laboratory analyzer "STA COMPACT" using "Diagnostica Stago" reagents. The laboratory investigation was initiated with global coagulation tests, including PT, APTT, and fibrinogen to assess blood clotting function.

The principle of the APCR study is a disproportionate prolongation of the clotting time, in the presence of $\mathrm{APC}$ and calcium. Before the test plasma is mixed with factor $\mathrm{V}$ deficient plasma, to ensure the normal starting concentration of the other factors. Clotting is initiated with Crotalus viridis helleri poison, which activates factor X [22]. Patients presenting a clotting time of $120 \mathrm{~s}$ or more were considered as APCR negative, whereas those with a clotting time less than $120 \mathrm{~s}$ were considered as APCR positive. For the prothrombin, the plasma level was determined. 
Functional assays for PC are either coagulometric or chromogenic methods. Both types of assays are based on the activation of PC in patient plasma using snake venom. The coagulometric assays are based on the ability of a patient's activated PC to degrade activated factors $\mathrm{V}$ and VIII, thereby prolonging the APTT-based clotting time. Laboratory investigation of PS deficiency is a clot-based method that measures the ability of PS to serve as a cofactor for activated PC, augmenting degradation of activated factors $\mathrm{V}$ and VIII and thereby prolonging clotting time. About the AT, the functional assays are chromogenic methods that measure AT activity related to its ability to inhibit thrombin (activated prothrombin) or activated factor X [23].

\section{Genotypic tests}

Due to financial considerations, the number of subjects was reduced to 60 in the study group and to 45 in the control group. Genomic DNA was extracted from blood samples using Wizard ${ }^{\circ}$ Genomic DNA Purification Kit from Promega.

FVL and prothrombin G20210A analysis was performed using a duplex PCR followed by restriction using a single endonuclease, HindIII. Primers for the factor $\mathrm{V}$ gene $61691 A$ determination and those for the prothrombin gene $620210 A$ determination are mentioned in Table 1. Thermocycling conditions are $94^{\circ} \mathrm{C}(1$ min), $58^{\circ} \mathrm{C}(1 \mathrm{~min})$, and $72^{\circ} \mathrm{C}(2 \mathrm{~min})$ for 40 cycles. The PCR products were digested with $15 \mathrm{U}$ of HindIII restriction enzyme. The restricted products were separated by electrophoresis through a $2 \%$ agarose gel stained with ethidium bromide and directly visualized under UV light. Figure 1 shows the different migration patterns observed. For both factor $\mathrm{V}$ and prothrombin alleles, the normal genotypes produce undigested PCR products (241 and 345 base pair (bp), respectively), whereas mutated homozygous lead to restricted fragments $(209+32$ and $322+23 \mathrm{bp}$, respectively). The heterozygous patterns are characterized by the presence of undigested and digested amplified fragments [24].

\section{Statistical analysis}

The statistical analysis was carried out using MINITAB (18.1). Continuous variables were expressed as mean, whereas categorical data were expressed in the form of frequency. The comparison between patient and control groups and the association between patients' clinical features and laboratory analysis were assessed using the chi-square $\left(\chi^{2}\right)$ test. A $p$ value $<0.05$ was considered statistically significant.

\section{Results}

A total of 180 subjects were included: 80 (44.44\%) cases and 100 controls. The demographic data of all participants are represented in Table 2.

Among the cases, the percentage of patients presenting a PC, PS, or AT deficiency is represented in Table 3.

By comparing the results of the screening tests between case and control groups, no significant difference has been found in the following parameters: APTT ( $p=$ $0.051)$, fibrinogen $(p=0.275)$, and prothrombin $(p=$ $0.434)$; however, the difference was statistically significant concerning PT $(p=0.024)$ and APCR $(p=0.011)$ (Table 4). Five cases of APCR were found in the patient group, whereas APCR was absent in controls.

FVL mutation was present in $5(8.33 \%)$ cases with the heterozygous form, while it was absent in all the controls (Table 5). FVL mutation was significantly associated with RPL $(p=0.047)$.

Prothrombin G20210A polymorphism was present in $5(8.33 \%)$ cases and in 5 (11.11\%) controls; consequently, no association was found between this polymorphism and the occurrence of RPL $(p=0.631)$ (Table 5).

Regarding the clinical features of patients, a significant correlation was found between the age and type of pregnancy loss $(p=0.01)$ and between age and number of pregnancy loss $(p=0.009)$. In fact, women older than 35 years presented more IUFD and have a high number of pregnancy loss $(>3)$.

A significant correlation was also found between $F V L$ and type of pregnancy loss $(p=0.001)$; the IUFD was more frequent than miscarriage in heterozygous patients.

Table 1 Specific primer sequences, restriction enzymes, and restriction digestion products' sizes for FVL and prothrombin G20210A. The PCR-RFLP products' sizes are given according to the genotype polymorphisms

\begin{tabular}{|c|c|c|c|c|c|c|}
\hline \multirow[t]{2}{*}{ Gene } & \multirow{2}{*}{$\begin{array}{l}\text { Length } \\
\text { (bp) }\end{array}$} & \multirow[t]{2}{*}{ Primer's sequence } & \multirow{2}{*}{$\begin{array}{l}\text { Restriction } \\
\text { enzyme }\end{array}$} & \multicolumn{3}{|c|}{ Restriction digestion product size (bp) } \\
\hline & & & & Normal & Heterozygous & Homozygous \\
\hline FVL & 241 & $\begin{array}{l}\text { Forward: 5'-TCAGGCAGGAACAAC } \\
\text { ACCAT-3' } \\
\text { Reverse: 5'-GGTTACTTCAAGGACA } \\
\text { AAATACCTGTAAAGCT-3' }\end{array}$ & HindIII & 241 & $241+209+32$ & $209+32$ \\
\hline Prothrombin & 345 & $\begin{array}{l}\text { Forward: 5'-TCTAGAAACAGTTGCC } \\
\text { TGGC-3' } \\
\text { Reverse: 5'-ATAGCACTGGGAGCAT } \\
\text { TGAAGC-3' }\end{array}$ & HindIII & 345 & $345+322+23$ & $322+23$ \\
\hline
\end{tabular}




\begin{tabular}{l}
$\begin{array}{l}\text { Sizes } \\
\text { (bp) }\end{array}$ \\
\hline
\end{tabular}

\section{Discussion}

Though the role of the two common thrombophilic mutations (FVL, prothrombin G20210A) in fetal loss has been well-studied in different populations, their real impact is still under debate. Therefore, it is of great importance to explore the association between these mutations and RPL in Algerian women. According to the results of our study, a significant correlation was found between $F V L$ and RPL occurrence, while no association was observed regarding prothrombin G20210A mutation.

As there is regional and ethnic variation in the distribution of mutations, we compared our rates firstly with reports from the same region. In Tunisia, Mahjoub et al. reported that the frequency of the mutant FV $(0.1400$ vs. $0.0276 ; p<0.001)$ but not prothrombin 20210 (0.0100 vs. $0.0225 ; p=0.159$ ) allele was higher in patients than controls, respectively. APCR with $F V L$ was seen in $27 \%$ of patients compared to $11.5 \%$ of controls, while APCR without FVL was seen in $12.5 \%$ of patients compared to $9.5 \%$ of controls [16]. In agreement with our results, they found that $F V L$ was a significant predictor for recurrent abortions.

In Saudi Arabia, a study showed that the frequencies of $F V L$ and prothrombin mutations among recurrent miscarriages patients were relatively high compared to general incidence supporting the hypothesis of considering them as RPL genetic factors [25].

A recent Turkish study reported a statistically meaningful data $(p<0.01)$ related to the relationship between RPL and thrombophilia-associated gene polymorphisms such as heterozygous $F V L$ and heterozygous prothrombin G20210A [26].

Unlike the results of the two previous studies, we found that prothrombin G20210A mutation was present in both case and control groups with heterozygous form and was not associated with the RPL. The same finding was observed by Silver et al. who tried to ascertain whether women carrying mutation of the prothrombin gene G20210A were at higher risk of RPL. They

Table 2 Demographic data of patient and control groups

\begin{tabular}{|c|c|c|c|c|}
\hline & & Study group & Control group & $\boldsymbol{p}$ value \\
\hline \multicolumn{2}{|l|}{ Number } & 80 & 100 & \\
\hline \multicolumn{2}{|l|}{ Age (years), mean (range) } & $33.28(19-45)$ & $32.84(21-45)$ & 0.94 \\
\hline \multicolumn{2}{|c|}{ Number of previous pregnancy loss, mean (range) } & $3(2-13)$ & - & \\
\hline \multirow[t]{3}{*}{ Type of pregnancy loss } & Miscarriage & 60 & - & \\
\hline & IUFD & 7 & & \\
\hline & Miscarriage + IUFD & 13 & & \\
\hline \multicolumn{2}{|c|}{ Number of participant with a previous live birth } & 46 & 100 & \\
\hline \multicolumn{2}{|l|}{ Consanguinity } & 18 & 10 & 0.021 \\
\hline \multicolumn{2}{|c|}{ Number of participant with a familial history of pregnancy loss } & 15 & 8 & 0.031 \\
\hline
\end{tabular}


Table 3 Results of screening tests of inherited thrombophilia in the case group

\begin{tabular}{lllll}
\hline Parameter & Frequency & Mean & Range & Normal range \\
\hline APCR & $5(6.25 \%)$ & 228.71 & $70.4-300$ & $120-300$ \\
PC & $6(7.5 \%)$ & 90.13 & $55-143$ & $70-130$ \\
PS & $6(7.5 \%)$ & 91.33 & $30-143$ & $55-140$ \\
AT & $3(3.75 \%)$ & 96.62 & $46-119$ & $80-120$ \\
\hline
\end{tabular}

recruited 5188 women, and 4167 blood samples were taken in the first trimester and analyzed for the gene mutation G20210A. Only 3.8\% of the women tested had a mutation of prothrombin G20210A, and their pregnancy loss rates were similar to those of women without the mutation. The authors thus concluded that the prothrombin gene mutation G20210A was not associated with pregnancy loss [27].

What was remarkable in our study is the high frequency of prothrombin G20210A mutation: $9.52 \%$ in all the studied population. In discordance with our finding, Liatsikos et al. [28] reported that the prevalence of this mutation varies from 0.2 to $3 \%$, being lowest in Africa $(0-0.3 \%)$ and highest in Southern Europe (3\%). The mean value in Northern Europe is $2 \%$. For $F V L$, its prevalence varies from 0.6 to $7.0 \%$, with the lowest frequency observed in Africa (0-0.6\%) and the highest in Southern Europe (7\%). The mean prevalence in Northern Europe is 4\% [29].

The 5 cases of APCR found by us were congenital as confirmed by the genotypic tests.

No homozygous case of $F V L$ was found in the study group, and all cases of $F V L$ mutation were found in second trimester. Kashif et al.'s [30] cases for $F V L$ mutation were also observed in the second trimester. However, Mahjoub et al. [16] found that $F V L$ was associated with early-late abortions. A systematic meta-analysis where late loss was defined as a pregnancy loss after the 24th week demonstrated a significant risk for early loss in homozygous $F V L$ but a lower, non-significant risk in heterozygous $F V L$. With respect to late loss (3rd trimester), there was a significant risk in heterozygous $F V L$ [31]. In fact, these differences can be explained by the heterogeneity in study designs, different definitions of

Table 4 Number of participants with normal values of coagulation tests

\begin{tabular}{llll}
\hline Parameter & Patients $(\boldsymbol{n}=80)$ & Controls $(\boldsymbol{n}=100)$ & $\boldsymbol{p}$ value \\
\hline PT & 76 & 100 & $\mathbf{0 . 0 2 4}$ \\
APTT & 77 & 100 & 0.051 \\
Fibrinogen & 60 & 83 & 0.275 \\
APCR & 75 & 100 & $\mathbf{0 . 0 1 1}$ \\
Prothrombin & 78 & 99 & 0.434 \\
\hline
\end{tabular}

Table 5 Distribution of FVL and prothrombin G20210A mutations in women with RPL and control women

\begin{tabular}{lllll}
\hline & Genotype & $\begin{array}{l}\text { Patients } \\
(\boldsymbol{n}=60)\end{array}$ & $\begin{array}{l}\text { Controls } \\
(\boldsymbol{n}=45)\end{array}$ & $\boldsymbol{p}$ value \\
\hline FVL & $\begin{array}{l}\text { Wild type } \\
\text { (GG) }\end{array}$ & 55 & 45 & $\mathbf{0 . 0 4 7}$ \\
& $\begin{array}{l}\text { Heterozygous } \\
\text { (AG) }\end{array}$ & 5 & 0 & \\
& $\begin{array}{l}\text { Homozygous } \\
\text { (AA) }\end{array}$ & 0 & 0 & \\
Prothrombin & $\begin{array}{l}\text { Wild type } \\
\text { (GG) }\end{array}$ & 55 & 40 & 0.631 \\
& $\begin{array}{l}\text { Heterozygous } \\
\text { (AG) }\end{array}$ & 5 & 5 & \\
& $\begin{array}{l}\text { Homozygous } \\
\text { (AA) }\end{array}$ & 0 & 0 & \\
\hline
\end{tabular}

late pregnancy loss among studies, and population heterogeneity.

Several studies have also investigated the link between other thrombophilic mutations-such as the methylenetetrahydrofolate reductase (MTHFR) and the plasminogen activator inhibitor-1 (PAI-1) polymorphisms-and the risk of RPL; however, the results remain controversial. For example, Dell'Edera et al. study indicated the absence of association between the two polymorphisms (C677T and A1298T) of the gene encoding the MTHFR and the RPL risk [32]. Another study realized by Li et al. suggested that PAI-1 4G/5G polymorphism might be associated with RPL development in Caucasians [33].

Regarding the association of PC and S with RPL, Gris et al. [34] and Parand et al. [12] found a significant association of RPL with PS deficiency and a non-significant correlation with PC deficiency. In our study, the frequency of these deficiencies was only determined in the study group so the comparison was not possible, but we have found the same frequencies for both proteins (7.5\%).

In terms of limitations, the study had subjects only from one ethnic group at only one center; also the number of participants was limited due to financial considerations. A larger sample size might be required to achieve an adequate statistical power. However, we permitted ourselves to evaluate the causal link using this small sample size since the results obtained are in alignment with previous works in this research area. In fact, our data provide further insight about the importance of testing for $F V L$ mutation in women who have experienced pregnancy losses and may be useful for further investigation about the role of anticoagulants in RPL.

In this subject, Leaf et al. [35] reported that the role of anticoagulants in the prevention of pregnancy complications, including recurrent miscarriage and late fetal loss, continues to be an area of active research. Although 
prophylactic anticoagulation with heparin and aspirin is considered the standard of care in obstetric antiphospholipid antibody syndrome [36], the optimal management of pregnant women with $F V L$ and other inherited thrombophilia without a history of thrombosis remains unknown. However, the low molecular weight heparindespite limited evidence of efficacy-is often used in an attempt to prevent these complications, owing to the lack of other effective treatments and its perceived safety in pregnancy [37].

\section{Conclusion}

Our study demonstrates the implication of $F V L$ mutation in the occurrence of RPL; for that, further study which will investigate the role of anticoagulants for pregnant women with a known FVL mutation is recommended and anticoagulation could be considered for future pregnancies of women with a RPL history with known $F V L$ mutation.

\section{Abbreviations}

APCR: Activated protein C resistance; APTT: Activated partial thromboplastin time; AT: Antithrombin; bp: Base pair; DNA: Deoxyribonucleic acid; EDTA: Ethylene diamine tetraacetic acid; FVL: Factor V Leiden; IUFD: Intrauterine fetal demise; MTHFR: Methylenetetrahydrofolate reductase; PAI1: Plasminogen activator inhibitor-1; PC: Protein C; PCR: Polymerase chain reaction; PS: Protein S; PT: Prothrombin time; RPL: Recurrent pregnancy loss; WA: Weeks of amenorrhea; $x^{2}$ : Chi-square test

\section{Acknowledgements}

We would like to acknowledge the participants and the supporting staff in this study for their immense support. The special thanks go to the laboratory of Hematology-Hospital Montpellier (France) for the help provided in the realization of genotypic tests. We thank also the team of the laboratory of Hematology - Tlemcen and the laboratory of Physiology, Physiopathology and Biochemistry of Nutrition-Tlemcen.

\section{Authors' contributions}

All authors contributed to the data interpretation and manuscript writing INM, KAT, BL, and AM designed the research and contributed to the data interpretation; INM and RiadB participated in the recruitment of subjects; INM performed the DNA extraction and genotyping; RedaB, AA, and AM performed the statistical analyses; INM, KAT, BL, RiadB, and HM interpreted the results; INM wrote the paper under the supervision of KAT; and BL had primary responsibility for the final content. All authors read and approved the final manuscript

\section{Funding}

This research did not receive any specific grant from funding agencies in the public, commercial, or not-for-profit sectors.

\section{Availability of data and materials}

The datasets used and/or analyzed during the current study are available from the first author Ilhem Nassour-Mokhtari (Ilhem_pharm@hotmail.fr) on reasonable request.

\section{Ethics approval and consent to participate}

The study was approved by the scientific ethics committee of the University of Tlemcen (decision reference: CEDUT/TLM/R027/2020). Everyone included in this study is informed and has given us written consent in accordance with Executive Decree No. 92-276 of 06 July 1992 on the Algerian Code of Medical Ethics.

\section{Consent for publication}

Not applicable.

\section{Competing interests}

All authors declare that they have no competing interests.

\section{Author details}

'Laboratory of Physiology, Physiopathology and Biochemistry of Nutrition, Faculty of Natural and Life Sciences, Earth and Universe, University of Tlemcen, 22, Rue Abi Ayed Abdelkrim Fg Pasteur B.P 119, 13000 Tlemcen, Algeria. ${ }^{2}$ National Center for Prehistoric, Anthropological and Historical Research (CNRPAH, Tlemcen's station), 03, Rue Franklin Roosevelt, 16500 Alger, Algeria. 'aboratory of Human Actions' Valorisation for Protection of Environment and Application in Public Health, University of Tlemcen, 22, Rue Abi Ayed Abdelkrim Fg Pasteur B.P 119, 13000 Tlemcen, Algeria. ${ }^{4}$ Gynecology and Obstetrics Department, Tlemcen's Teaching Hospital, 05, Bd Mohammed $\checkmark$, Tlemcen, Algeria. ${ }^{5}$ Hematology Department, Tlemcen's Teaching Hospital, 05, Bd Mohammed V, Tlemcen, Algeria.

Received: 16 February 2020 Accepted: 19 June 2020

Published online: 17 August 2020

\section{References}

1. Sarig G, Younis JS, Hoffman R, Lanir N, Blumenfeld Z, Brenner B (2002) Thrombophilia is common in women with idiopathic pregnancy loss and is associated with late pregnancy wastage. Fertil Steril 77(2):342-347

2. Edmonds D. Keith. Dewhurst's textbook of obstetrics and gynaecology. Edition E, editor: Wiley-Blackwell, UK; 2011

3. Jauniaux E, Farquharson RG, Christiansen OB, Exalto N (2006) Evidencebased guidelines for the investigation and medical treatment of recurrent miscarriage. Human reproduction (Oxford, England) 21(9):2216-2222

4. Branch DW HC. Reproductive endocrinology and infertility: integrating modern clinical and laboratory practice 2010

5. Jaslow CR, Carney JL, Kutteh WH (2010) Diagnostic factors identified in 1020 women with two versus three or more recurrent pregnancy losses. Fertil Steril 93(4):1234-1243

6. Rai R, Regan L (2006) Recurrent miscarriage. Lancet (London, England) 368(9535):601-611

7. Bereziuk OM, Mazur JV, Berko GK, Perebetiuk LS, Velychkovych MM, Temna OV et al (2019) Primary and secondary thrombophilia: pathogenesis, clinical presentation, approaches to thrombotic complications prevention and treatment. Wiad Lek 72 (5 cz 1):908-913.

8. Dugalic S, Petronijevic M, Stefanovic A, Stefanovic K, Perovic M, Pantic I et al (2019) Perinatal complications related to inherited thrombophilia: review of evidence in different regions of the world. J Matern Fetal Neonatal Med:110

9. Visser J, Ulander VM, Helmerhorst FM, Lampinen K, Morin-Papunen L, Bloemenkamp KW et al (2011) Thromboprophylaxis for recurrent miscarriage in women with or without thrombophilia. HABENOX: a randomised multicentre trial. Thromb Haemost 105(2):295-301

10. Colman-Brochu S (2004) Deep vein thrombosis in pregnancy. MCN The American journal of maternal child nursing 29(3):186-192

11. Gozdziewicz TWM, Lojewski AA, Skrzypczak J (2013) The assessment of causes of recurrent pregnancy loss in material of the division of reproduction at Poznan University of Medical Sciences. Archives of Perinatal Medicine 19(2):81-87

12. Parand A, Zolghadri J, Nezam M, Afrasiabi A, Haghpanah S, Karimi M (2013) Inherited thrombophilia and recurrent pregnancy loss. Iran Red Crescent Med J 15(12):e13708

13. Kupferminc MJ (2003) Thrombophilia and pregnancy. Reproductive biology and endocrinology : RB\&E 1:111

14. Greer JPFJ, Rodger GM, Paraskevas F, Glader B, Arber DA (2009) Wintrobe's clinical hematology, 12th edn. Wolters Kluwer Health/Lippincott Williams \& Wilkins, Philadelphia

15. Lindqvist $P G$, Svensson PJ, Marsaal $K$, Grennert L, Luterkort M, Dahlback B (1999) Activated protein C resistance (FV:Q506) and pregnancy. Thromb Haemost 81(4):532-537

16. Mahjoub T, Mtiraoui N, Tamim H, Hizem S, Finan RR, Nsiri B et al (2005) Association between adverse pregnancy outcomes and maternal factor $\mathrm{V}$ G1691A (Leiden) and prothrombin G20210A genotypes in women with a history of recurrent idiopathic miscarriages. Am J Hematol 80(1):12-19

17. Cosmi B, Legnani C, Pengo V, Ghirarduzzi A, Testa S, Poli D et al (2013) The influence of factor $V$ Leiden and G20210A prothrombin mutation on the 
presence of residual vein obstruction after idiopathic deep-vein thrombosis of the lower limbs. Thromb Haemost 109(3):510-516

18. Yildiz G, Yavuzcan A, Yildiz P, Suer N, Tandogan N (2012) Inherited thrombophilia with recurrent pregnancy loss in Turkish women--a real phenomenon? Ginekol Pol 83(8):598-603

19. Hussein AS, Darwish H, Shelbayeh K (2010) Association between factor V Leiden mutation and poor pregnancy outcomes among Palestinian women. Thromb Res 126(2):e78-e82

20. D'Uva M, Micco PD, Strina I, Placido GD (2010) Recurrent pregnancy loss and thrombophilia. Journal of clinical medicine research 2(1):18-22

21. Wojcieszek AM, Shepherd E, Middleton P, Lassi ZS, Wilson T, Murphy MM et al (2018) Care prior to and during subsequent pregnancies following stillbirth for improving outcomes. Cochrane Database Syst Rev 12(12): CD012203

22. Abraitis V, Simoliuniene R, Mongirdiene A, Makari S (2004) Prevalence of activated protein $C$ resistance among women with recurrent miscarriage. Medicina (Kaunas, Lithuania) 40(3):225-231

23. Margetic S (2014) Laboratory investigation of thrombophilia. J Med Biochem 33:28-46

24. Muriel G, Christine B, Philippe J, Christophe M, Francois SJ, Patricia AM (1998) An even easier method for one-step detection of both FV Leiden and Fll G20210A transition. Blood. 92(9):3478-3479

25. Turki RF, Assidi M, Banni HA, Zahed HA, Karim S, Schulten HJ et al (2016) Associations of recurrent miscarriages with chromosomal abnormalities, thrombophilia allelic polymorphisms and/or consanguinity in Saudi Arabia. BMC medical genetics 17(Suppl 1):69

26. Barut MU, Bozkurt M, Kahraman M, Yildirim E, Imirzalioglu N, Kubar A et al (2018) Thrombophilia and recurrent pregnancy loss: the enigma continues. Medical science monitor : international medical journal of experimental and clinical research 24:4288-4294

27. Silver RM, Zhao Y, Spong CY, Sibai B, Wendel G Jr, Wenstrom K et al (2010) Prothrombin gene G20210A mutation and obstetric complications. Obstet Gynecol 115(1):14-20

28. Liatsikos SA, Tsikouras P, Manav B, Csorba R, von Tempelhoff GF, Galazios G (2016) Inherited thrombophilia and reproductive disorders. J Turk Ger Gynecol Assoc 17(1):45-50

29. Benedetto C, Marozio L, Tavella AM, Salton L, Grivon S, Di Giampaolo F (2010) Coagulation disorders in pregnancy: acquired and inherited thrombophilias. Ann N Y Acad Sci 1205:106-117

30. Kashif S, Kashif MA, Saeed A (2015) The association of factor V Leiden mutation with recurrent pregnancy loss. JPMA The Journal of the Pakistan Medical Association 65(11):1169-1172

31. Wu O, Robertson L, Twaddle S, Lowe GD, Clark P, Greaves M et al (2006) Screening for thrombophilia in high-risk situations: systematic review and costeffectiveness analysis. The thrombosis: risk and economic assessment of thrombophilia screening (TREATS) study. Health Technol Assess 10(11):1-110

32. Dell'Edera D, L'Episcopia A, Simone F, Lupo MG, Epifania AA, Allegretti A (2018) Methylenetetrahydrofolate reductase gene C677T and A1298C polymorphisms and susceptibility to recurrent pregnancy loss. Biomed Rep 8(2):172-175

33. Li X, Liu Y, Zhang R, Tan J, Chen L, Liu Y (2015) Meta-analysis of the association between plasminogen activator inhibitor-1 4G/5G polymorphism and recurrent pregnancy loss. Medical science monitor : international medical journal of experimental and clinical research. 21:1051-1056

34. Gris JC, Quere I, Monpeyroux F, Mercier E, Ripart-Neveu S, Tailland ML et al (1999) Case-control study of the frequency of thrombophilic disorders in couples with late foetal loss and no thrombotic antecedent--the Nimes obstetricians and Haematologists Study5 (NOHA5). Thromb Haemost 81(6): 891-899

35. Leaf RK, Connors JM (2017) The role of anticoagulants in the prevention of pregnancy complications. Clin Appl Thromb Hemost 23(2):116-123

36. Bouvier S, Cochery-Nouvellon E, Lavigne-Lissalde G, Mercier E, Marchetti T, Balducchi JP et al (2014) Comparative incidence of pregnancy outcomes in treated obstetric antiphospholipid syndrome: the NOH-APS observational study. Blood. 123(3):404-413

37. Ormesher L, Simcox L, Tower C, Greer IA (2016) Management of inherited thrombophilia in pregnancy. Womens Health (Lond) 12(4):433-441

\section{Publisher's Note}

Springer Nature remains neutral with regard to jurisdictional claims in published maps and institutional affiliations.

\section{Submit your manuscript to a SpringerOpen ${ }^{\circ}$ journal and benefit from:}

- Convenient online submission

- Rigorous peer review

- Open access: articles freely available online

High visibility within the field

- Retaining the copyright to your article

Submit your next manuscript at $\boldsymbol{\nabla}$ springeropen.com 